\title{
Sea Level Variations in the Regional Seas around Taiwan
}

\author{
Yu-Heng Tseng ${ }^{1 *}$, Larry C. Breaker ${ }^{2}$ and Emmy T.-Y. Chang $^{3}$ \\ ${ }^{I}$ Department of Atmospheric Sciences, National Taiwan University, \\ No. 1, Sec. 4, Roosevelt Rd., Taipei 106, Taiwan \\ ${ }^{2}$ Moss Landing Marine Laboratories, 8272 Moss Landing Rd, Moss Landing, CA 95039, U.S.A. \\ ${ }^{3}$ Institute of Oceanography, National Taiwan University, \\ No. 1, Sec. 4, Roosevelt Rd., Taipei 106, Taiwan
}

(Received 5 January 2009; in revised form 22 June 2009; accepted 8 August 2009)

\begin{abstract}
The patterns and trends of sea level rise in the regional seas around Taiwan have been investigated through the analyses of long-term tide-gauge and satellite altimetry data. Series of tide-gauge data extending over 50 years reveal decadal and interannual variations and spatially-inhomogeneous patterns of generally rising sea level. The East Asia tide-gauge stations around Taiwan show an average trend of $+2.4 \mathrm{~mm} / \mathrm{yr}$ from 1961-2003, which is larger than the reported global rate of $+1.8 \mathrm{~mm} / \mathrm{yr}$ for the same period. These stations also show significantly larger sea level rise rates $(+5.7$ $\mathrm{mm} / \mathrm{yr})$ than global values $(+3.1 \mathrm{~mm} / \mathrm{yr})$ during the period from 1993-2003. Consistent with the coastal tide-gauge records, satellite altimetry data show similar increasing rates $(+5.3 \mathrm{~mm} / \mathrm{yr})$ around Taiwan during the same period. Comparisons with temperature anomalies in the upper ocean suggest that thermal expansion and heat advection in the upper layer contribute significantly to the long-term sea level variations in this area with correlations $>0.9$ for observations after 1992 . Thermosteric sea level variations may also explain the interannual and decadal variations of the observed sea level rises around Taiwan. Our analysis also indicates that the altimetry data are only part of a long-term, larger-scale signal. Finally, we have found that a non-linear smoother, LOESS, is more suitable for extracting long-term trends in sea level than the traditional linear regression approach.
\end{abstract}

\section{Introduction}

Estimates of twentieth century Sea Level Rise (SLR) are primarily based on coastal tide gauges, which measure the sea surface height relative to coastal benchmarks and often provide long, unique time series. In general, global SLR results from two mechanisms: (1) steric effects: volume change due to seawater density change in response to temperature (thermosteric) and salinity (halosteric) variations; and (2) eustatic effects: mass change due to exchange of water with the atmosphere and continents, such as from glaciers and ice sheets, through precipitation, evaporation, river runoff, and ice melting. However, these latter processes are not currently well understood.

Although coastal tide gauges provide the longest records for estimating SLR, such measurements may in-

\footnotetext{
* Corresponding author. E-mail: yhtseng@as.ntu.edu.tw Copyright $\odot$ The Oceanographic Society of Japan/TERRAPUB/Springer
}

Keywords:

- Sea level rise,

- ENSO,

- decadal oscillation. clude other signals, such as local subsidence, tectonic motion, and secular trends in vertical movement of the earth's crust and sea surface, e.g., Glacial Isostatic Adjustment (GIA). The GIA is due to the transfer of mass from the ice sheets to the oceans, thus alleviating the loading of the earth, and small spatial-scale tectonic motions (Intergovernmental Panel on Climate Change, IPCC, 2007). The GIA effect can often be roughly corrected for using geophysical models (e.g., Tushingham and Peltier, 1991), but the local tectonic motions are not easy to detect and estimate. Douglas (1997) estimated a globally averaged SLR rate of $+1.8 \mathrm{~mm} / \mathrm{yr}$ using twenty-four tidegauge records after applying GIA corrections. Miller and Douglas (2004) further showed that the 20th century SLR was $+1.5 \sim 2.0 \mathrm{~mm} / \mathrm{yr}$, which includes both volume (steric) and mass (eustatic) changes. This is approximately $2 \sim 3$ times greater than the rates $(+0.5 \mathrm{~mm} / \mathrm{yr})$ due to volume changes derived from temperature and salinity data only. Satellite-based estimates suggest that SLR has increased at an even faster rate of $+2.8 \pm 0.4 \mathrm{~mm} / \mathrm{yr}$ since the $1990 \mathrm{~s}$ (IPCC, 2007). 


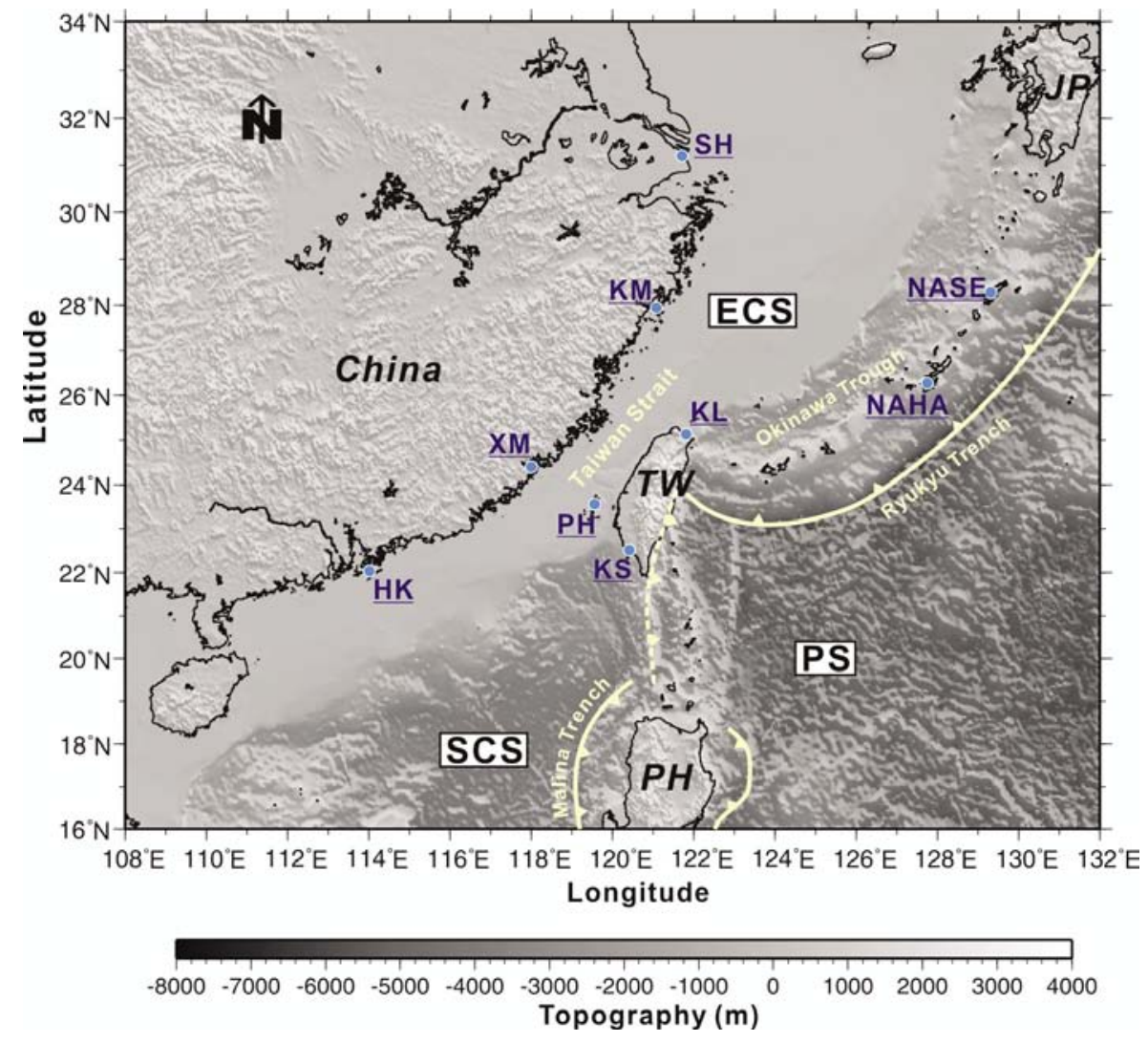

Fig. 1. Regional seas around Taiwan and the tide-gauge stations used in this study. Taiwan is surrounded by South China Sea (SCS), Philippine Sea (PS), East China Sea (ECS) and Taiwan Strait. Taiwan Strait is a 200-km-wide shallow passage between Taiwan and China. Tectonic plates are also shown. Abbreviations are: JP: Japan, here is Kyushu island; PH: Philippine, here is northern Luzon; TW: Taiwan. A major fault line constitutes a convergent boundary east of Taiwan (both the yellow dashed lines and solid lines). Information on tide gauge stations is detailed in Table 1.

Furthermore, some studies suggest that regional differences in atmospheric and oceanic forcing may contribute to large spatial variations in the rate of global SLR (e.g., Church et al., 2004). Larger rates of SLR have been identified in the western tropical Pacific, eastern Indian, and Southern oceans during the last decade (Li et al., 2002; Cazenave and Nerem, 2004). These studies have revealed the importance of regional SLR and an understanding of its causes. Few sea level studies have been conducted in the regional seas around Taiwan, and none has yet focused on the potential impacts of SLR on Taiwan. Chen (1991) reported SLR at the Changjiang river mouth since the early 1920s. Wang (1998) further estimated the rate of SLR of $+2 \sim 3 \mathrm{~mm} / \mathrm{yr}$ along the coast of China during the last century. Overpumping of groundwater and overloading of the delta plain and lowland coast by construction have had serious effects: the average rate of relative SLR is $+24.5 \sim 50 \mathrm{~mm} / \mathrm{yr}$ in Tianjing (north China) and $+6.5 \sim 11.0 \mathrm{~mm} / \mathrm{yr}$ in the Shanghai (SH) area of the Changjiang River (see locations of cities in Fig.
$1)$.

Recently, Li et al. (2002) used TOPEX/Poseidon $(\mathrm{T} / \mathrm{P})$ satellite altimetry data to study the general trend in sea level variation in the South China Sea (SCS) between 1993 and 2000. They found a rise rate of $\sim+10 \mathrm{~mm} / \mathrm{yr}$ with the highest rate of $+27 \mathrm{~mm} / \mathrm{yr}$ near the west of Luzon and generally lower rates over the shallow continental shelves. They attributed the rapid rise in sea level to the rapid warming of the upper layer in the SCS. Cheng and Qi (2007) further analyzed longer satellite altimetry data series (October 1992 January 2006) in the SCS. They found a rise rate of $+11.3 \mathrm{~mm} / \mathrm{yr}$ during 1993 2000 and, subsequently, a descending rate of $-11.8 \mathrm{~mm} / \mathrm{yr}$ during 2001 2005. The asymmetric distribution of sea level variations over the SCS suggests pronounced variations in this area and the influence of thermal advection.

Levitus et al. (2000) showed that the world's oceans have been warming over the last 50 years, with substantial changes in heat content occurring in the upper $300 \mathrm{~m}$ to $1000 \mathrm{~m}$ in each ocean. Substantial changes in North 
Atlantic heat content also occur at depths greater than $1000 \mathrm{~m}$. Levitus et al. (2005) further estimated that the global oceanic heat content (OHC) increased by approximately $14.5 \times 10^{22} \mathrm{~J}$ during $1955 \sim 1998$. The global mean temperature also increased by $0.037^{\circ} \mathrm{C}$ for the whole ocean $(0-3000 \mathrm{~m})$ and $0.171^{\circ} \mathrm{C}$ for the upper layer $(0$ $300 \mathrm{~m}$ ). Thermal expansion associated with this warming of the ocean should be associated with a corresponding SLR. Cabanes et al. (2001) reported that the global mean SLR over 1993 2000 reached +3.2 $\pm 0.2 \mathrm{~mm} / \mathrm{yr}$, which is close to the estimated $3.1 \pm 0.4 \mathrm{~mm} / \mathrm{yr}$ based on thermosteric SLR integrated down to $500 \mathrm{~m}$. They also showed that the thermosteric SLR was $+0.5 \pm 0.05$ $\mathrm{mm} / \mathrm{yr}$ during 1955 1996. Using salinity data for 1957 1994, Antonov et al. (2002) suggested that the input of fresh water to the oceans could explain the remaining SLR. A decrease in global mean salinity during 1957 1994 and this equivalent increase in fresh water could cause global sea level to increase at a rate of $+1.3 \pm$ $0.5 \mathrm{~mm} / \mathrm{yr}$, if the added water came from sources other than floating sea ice. Moreover, their data also revealed spatially-inhomogeneous (Antonov et al., 2002).

Taiwan is an isolated island located at the western edge of the Pacific, at the conjunction of the East China Sea (ECS), the Philippine Sea (PS), and the SCS. An active tectonic oblique convergence exists around Taiwan, so the island is considered to have been tectonically active for the past two million years (Ho, 1986). The surrounding bathymetry is complicated (Fig. 1). West of the Taiwan island lies the Taiwan Strait, a 200-km-wide, shallow passage (less than $100 \mathrm{~m}$ in general) between Taiwan and mainland China. The Taiwan Strait is part of the continental margin sea off eastern China. It forms a topographic barrier inhibiting intermediate- and deep-water circulation. East of Taiwan, the bathymetry drops rapidly down to $4000 \mathrm{~m}$ from the coastline. This steep relief is truncated by the Ryukyu Trench and the Okinawa Trough to the north, which correspond to the northward subduction of the Philippine Sea basin beneath the southeast Chinese continental margin (Fig. 1). South of the island of Taiwan lies the Luzon-Philippine Archipelago, which is the product of the SCS subduction eastward beneath the Philippine Sea basin. A recent study showed that seamount topography along the northern Luzon-Philippine Archipelago constrains the Kuroshio, causing it to remain primarily in the Pacific Ocean and thus not intrude far into the SCS (Metzger and Hurlburt, 2001; Du et al., 2008).

The main objective of this study is to reconstruct the long-term trends of sea level variation in the regional seas around Taiwan and investigate the possible causes of regional SLR. The critical questions we try to answer are: (1) What are the rates of SLR and their long-term variation in the regional seas around Taiwan? (2) How do these rates of SLR compare with those at other locations around the world? (3) What are the possible causes of the SLR in this area? To our knowledge, long-term sea level variations in the regional seas around Taiwan have not been examined and discussed in the literature except for the SCS. Moreover, the physical processes affecting sea level variations are not well understood. In this study, more than 50 years of tide-gauge data have been used to investigate the long-term variations in sea level in the vicinity of Taiwan. Fifteen years of recent satellite altimetry data are also used for comparison and validation.

This paper is organized as follows. Section 2 briefly introduces the data sources and methods. Section 3 presents the long-term tide-gauge and satellite altimetry results. Section 4 discusses some possible mechanisms responsible for the SLR. Finally, conclusions are given in Section 5.

\section{Data Sources and Methods}

The data used for our analyses consist of more than 50 years of tide-gauge data (1947 2007 for the longest series) and 15 years of altimetry data. Additional subsurface time series temperature data (Ishii et al., 2006) are also used for comparison. Both tide-gauge and altimetry data are described in this section.

We have not attempted to apply corrections for GIA or for the inverted barometer effect due to sea level pressure (SLP) in this study. To our knowledge, GIA corrections have yet to be calculated for the study area due to its low latitude (around $23.5^{\circ} \mathrm{N}$ ). Furthermore, the expected time scales associated with GIA adjustments are far longer than the time scales of variability in sea level that we consider, and the magnitudes of these corrections are often far smaller than the magnitudes of the sea level variability that we have observed. We have not applied corrections for SLP because, in many cases, there are no exact observations of SLP at the tide-gauge locations, or not exist for the full duration of the tide-gauge records. According to Chelton and Enfield (1986), efforts to separate the local inverted barometer response from other sources of sea level variability have largely been unsuccessful. Finally, it is doubtful that such a correction, if it were applied, would significantly affect any of our conclusions because the magnitudes of variability encountered were relatively large, making it easier to identify the most likely sources of variability.

\subsection{The tide-gauge dataset}

Figure 1 shows the tide-gauge stations used in this study. The data come from two major data sources: the Central Weather Bureau (CWB), Taiwan, and the Permanent Service for Mean Sea Level (PSMSL (http:// www.pol.ac.uk/psmsl/)) in Liverpool, England (Woodworth and Player, 2003). Information related to 
Table 1. Tide-gauge stations in the regional seas around Taiwan (used in this study). The official code numbers are directly obtained from the CWB and PSMSL records.

\begin{tabular}{|c|c|c|c|c|c|c|}
\hline \multicolumn{3}{|c|}{ Station/official code number } & \multirow{2}{*}{$\frac{\text { Location }}{22.3^{\circ} \mathrm{N}, 114.2^{\circ} \mathrm{E}}$} & \multirow{2}{*}{$\frac{\text { Time (year, month) }}{198601 \sim 200612}$} & \multirow{2}{*}{$\frac{\text { Source }}{\text { PSMSL }}$} & \multirow{2}{*}{$\begin{array}{c}\text { Final series } \\
195004 \sim 200612\end{array}$} \\
\hline Hong Kong (HK) & QB & 611010 & & & & \\
\hline & NP & 611011 & & $192904 \sim 198512$ & & \\
\hline & $\mathrm{TP}$ & 611014 & & $196301 \sim 200612$ & & $196301 \sim 200612$ \\
\hline Kanmen (KM) & 610016 & & $28.1^{\circ} \mathrm{N}, 121.3^{\circ} \mathrm{E}$ & $195901 \sim 200712$ & PSMSL & $195901 \sim 200712$ \\
\hline \multirow[t]{5}{*}{ Kaohsiung (KS) } & 148 & & $22.6^{\circ} \mathrm{N}, 120.3^{\circ} \mathrm{E}$ & $198701 \sim 200807$ & CWB & $194705 \sim 200712$ \\
\hline & 1481 & & & $199707 \sim 199806$ & & \\
\hline & 1482 & & & $194705 \sim 198612$ & & \\
\hline & 1486 & & & $200403 \sim 200808$ & & \\
\hline & 612012 & & & $197301 \sim 198912$ & PSMSL & - \\
\hline \multirow[t]{6}{*}{ Keelung (KL) } & 1212 & & $25.2^{\circ} \mathrm{N}, 121.7^{\circ} \mathrm{E}$ & $194605 \sim 199012$ & CWB & 194801 200612 \\
\hline & 151 & & & $199503 \sim 200012$ & & \\
\hline & 1511 & & & $199101 \sim 199503$ & & \\
\hline & 1513 & & & $200401 \sim 200712$ & & \\
\hline & 1516 & & & $200711 \sim 200808$ & & \\
\hline & 612002 & & & $195601 \sim 199512$ & PSMSL & - \\
\hline NAHA (NH) & 646024 & & $26.2^{\circ} \mathrm{N}, 127.7^{\circ} \mathrm{E}$ & 196608 200712 & PSMSL & 196608 200712 \\
\hline \multirow[t]{3}{*}{ NASE (NS) } & I & 646001 & $28.4^{\circ} \mathrm{N}, 129.5^{\circ} \mathrm{E}$ & $195704 \sim 196112$ & PSMSL & $195701 \sim 200712$ \\
\hline & II & 646002 & & $196201 \sim 198012$ & & \\
\hline & III & 646003 & & $198101 \sim 200712$ & & \\
\hline Penghu (PH) & 1351 & & $23.5^{\circ} \mathrm{N}, 119.5^{\circ} \mathrm{E}$ & $195503 \sim 200612$ & CWB & $195503 \sim 200612$ \\
\hline Xiamen (XM) & 610016 & & $24.5^{\circ} \mathrm{N}, 118.1^{\circ} \mathrm{E}$ & $195501 \sim 200412$ & PSMSL & $195501 \sim 200412$ \\
\hline
\end{tabular}

each station is also given in Table 1, including information on any movement of the stations. For data sources from CWB, apparent location changes appear for some stations due to changes of management, actual movement of stations, and changes of baselines (see Table 1). All datums are screened carefully for possible artificial datum shifting. For the Taiwan area, we selected three representative stations (Fig. 1) from the CWB tide-gauge database. Keelung has the longest time series (dating back to 1946) and is located in north Taiwan. Kaohsiung is located near south Taiwan. Penghu is unique because it is a small island between Taiwan and mainland China in the middle of the Taiwan Strait (Fig. 1). All of these stations have long, continuous records. Other CWB stations, such as Taichung and Wunkang, also have long time series but the existence of major gaps limits their overall usefulness in long-term evaluations, and thus they have been excluded from this study.

All other monthly observations of mean sea level used here have been obtained from the PSMSL
(Woodworth and Player, 2003), which includes 287 tidegauge stations around the world that are part of the Global Sea Level Observing System (GLOSS) monitoring oceanographic sea level and climate change. Note that both Kaohsiung and Keelung are also available from the PSMSL database but with a few incomplete records. We have therefore used the complete records from the CWB database in these areas. The sea level data used in this study are monthly mean values. Note that the "Revised Local Reference" (RLR) data are used here, which are supported by documentation relating measured sea level at each station to a constant local datum over the complete record.

Since our study emphasizes long-term trends in SLR in the vicinity of Taiwan, the low-frequency tidal components such as the nodal tide, which has a period of 18.61 years, may affect the record. However, early studies indicated that the nodal tide amplitude is latitude dependent, with maxima near the equator and the poles (Lisitzin, 1974). The amplitude is almost negligible between 30- 


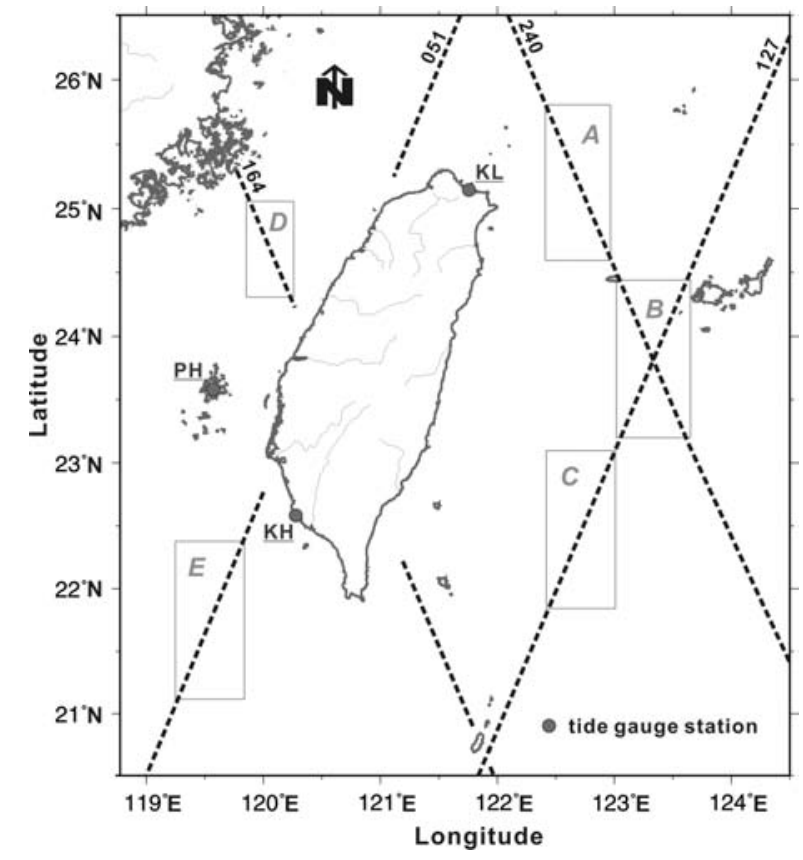

Fig. 2. Altimetry tracks used in this study represented as black dash-lines; track numbers are indicated. The adopted segments for determined SRL are zoned by rectangles, selected with five regions (A-E) around Taiwan.

$40^{\circ} \mathrm{N}$. These features are also typical of the other longperiod tidal constituents. Indeed, comparison after removing harmonic nodal mode shows that the influence of longterm nodal tide on our records is minimal for the latitudes of interest in this study (not shown).

The longest record we employ (Kaohsiung) begins in May 1947 and ends in December 2007, spanning a period of 60 years. Fewer than $0.5 \%$ of the data are missing from each record, so we have used interpolation to complete the time series in each case. It is well known that the island of Taiwan is tectonically active and that there is a major fault line that constitutes a convergent boundary east of Taiwan (presented by both yellow dashed lines and solid lines in Fig. 1). Therefore, we do not consider the tide-gauge stations along the east coast, where greater vertical motion is expected. The measurement sites chosen for this study are located on the same tectonic plate and any vertical displacement due to the plate motion is assumed to be small. Tectonic influences in this study area will be discussed further in a separate paper.

\subsection{Satellite altimetry}

Since the tide-gauge measurements include many other contributions, such as tectonic movements and local subsidence or uplift, and observations are limited to coastal regions, satellite altimetry provides an alternative for detecting regional sea level variations with more com-
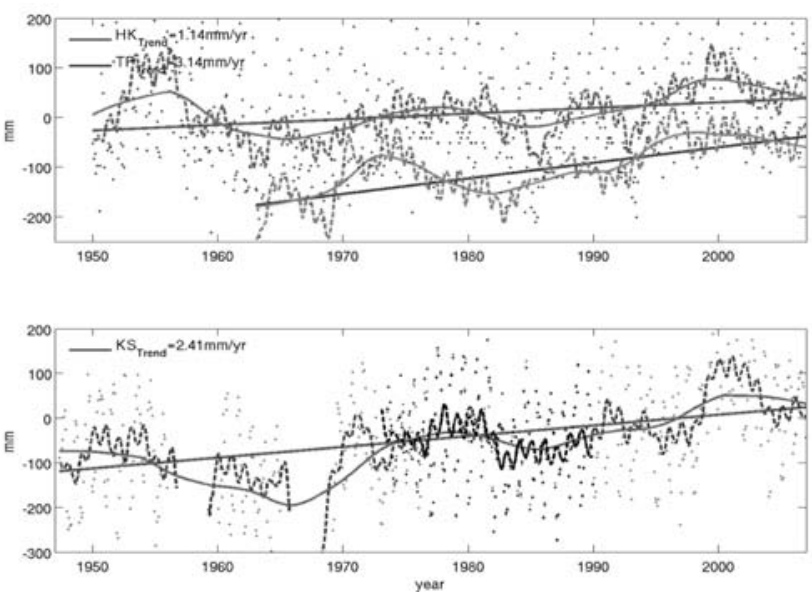

(a)
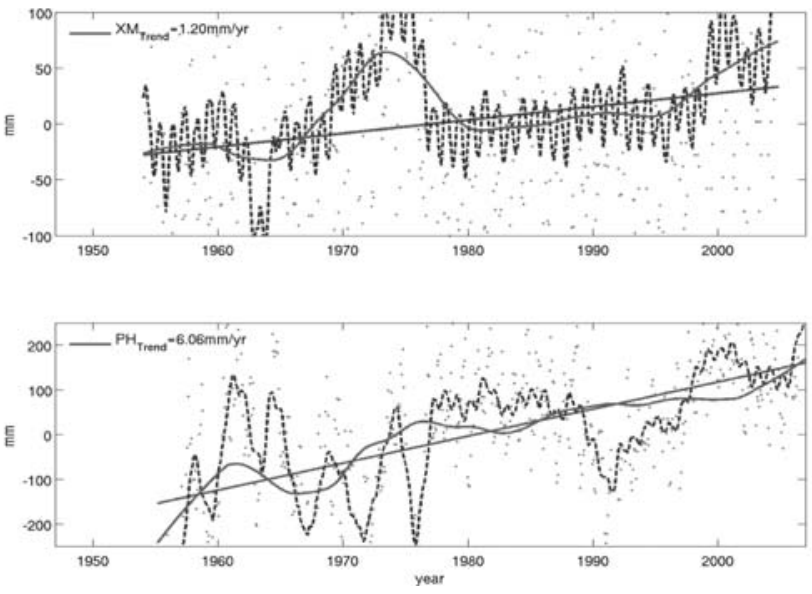

(b)

Fig. 3. Monthly observations of relative sea levels and their trends at (a) Hong Kong (HK) and Kaohsiung (KS); and (b) Xiamen (XM) and Penghu (PH). Two nearby obervations (HK and TP, see Table 1) are shown in Hong Kong according to the PSMSL records. HK combines the original data from two continuous stations (QB and NP, see Table 1). Straight lines are linear trends for the whole observation period based on robust linear regression, while solid curves are the non-linear variations estimated by the LOESS analysis (see texts). Eighteen-month moving mean filters (shown as dash lines) are also applied to the scattered observation (shown as dots) in order to remove the annual or other high frequency signal.

prehensive spatial coverage. To estimate relative SLR in recent years, we also use 15 years of altimetry data from the Radar Altimeter Database System (RADS) from 1993 to 2007 (Schrama et al., 2000). The RADS altimetry data are used for comparison and validation. RADS provides a well validated and cross-calibrated sea level dataset, including European Remote Sensing (ERS), T/P, and GEOdetic SATellite (GEOSAT) data. It operates within 

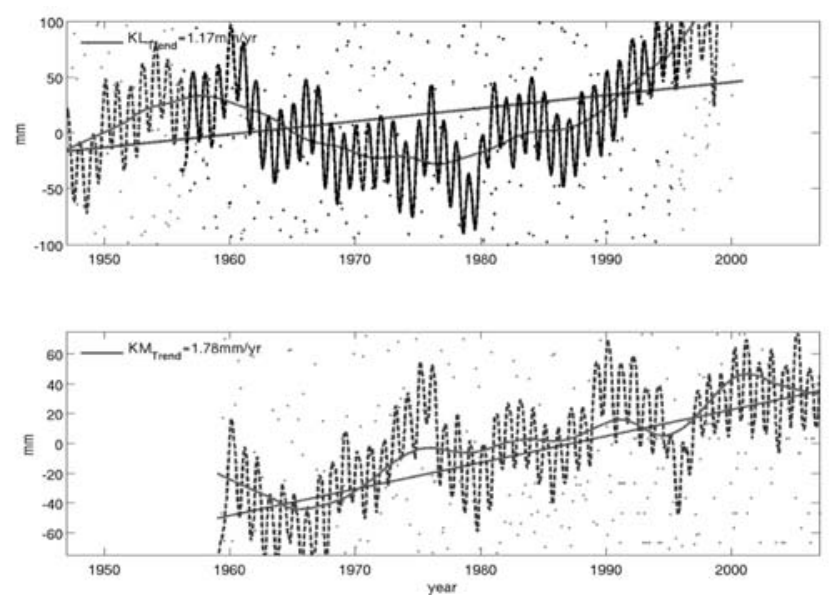

(a)
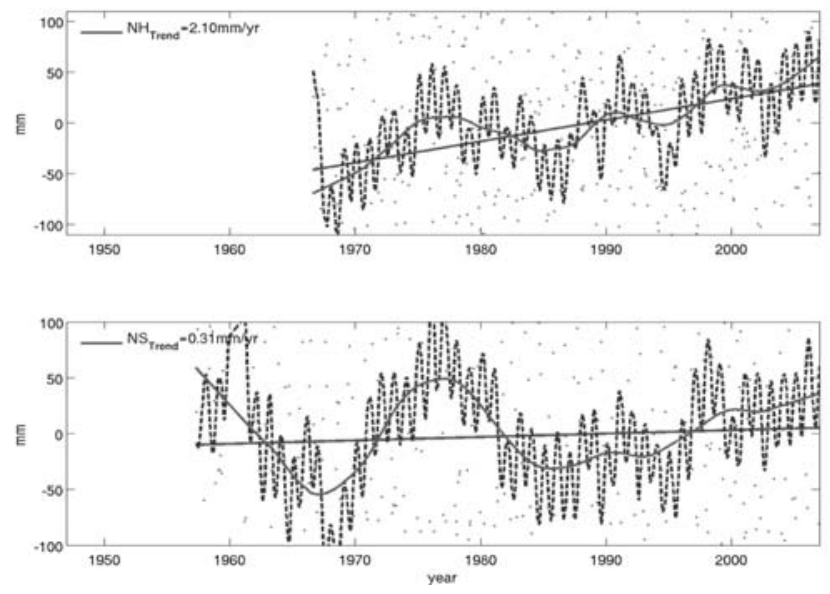

(b)

Fig. 4. As Fig. 3 but for different tide-gauge stations. (a) Keelung (KL) and Kanmen (KM); and (b) NASE (NS) and NAHA $(\mathrm{NH})$ in Japan.

the framework of the Netherlands Earth Observation NETwork, NEONET, an Internet facility funded by the Dutch government. Figure 2 shows the altimetry tracks used in this study, where we have divided the seas around Taiwan into five regions (A-E).

\section{Results}

\subsection{Estimating long-term (decadal) trends from the tide- gauge records}

First, we show the sea level data observed at several different stations and plotted in millimeters $(\mathrm{mm})$ as a function of time. Monthly mean sea levels and their trends over a period of more than 50 years are shown in Figs. 3 and 4 . These panels are ordered based on the individual station's relative tectonic plate location and latitude. Figure 3(a) shows the monthly observations of relative sea

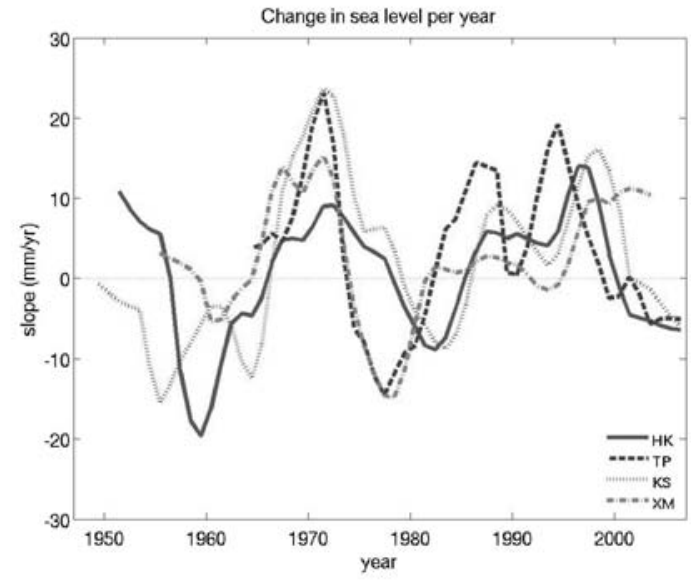

(a)

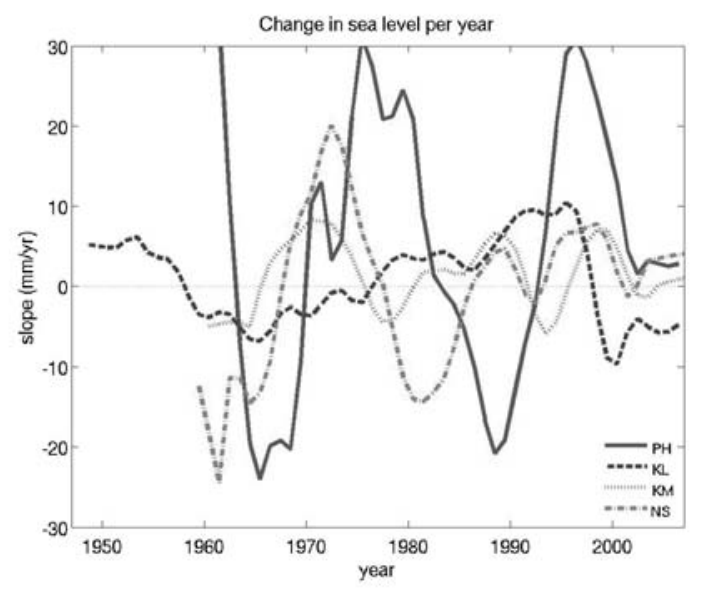

(b)

Fig. 5. Comparison of the yearly forward first differences of the LOESS analysis for all stations. Curves show the change in sea levels each year ( $\mathrm{mm} / \mathrm{yr})$. Average of all slopes during a particular period represents the long-term mean slope (i.e. linear trend) for that period.

level at Hong Kong and Kaohsiung for the period from 1950 through 2007. Both locations reflect similar coastal responses around the SCS. In order to remove the seasonal, annual, or other high frequency signals, an 18month moving mean filter (shown as dashed lines) has been applied to the scattered observations (shown as dots). The moving mean filter is commonly used to estimate SLR and is well known to distort the content of the signal in the frequency domain (e.g., Emery and Thomson, 2004). Its major problem is its inability to identify nonlinear variations such as the length or duration of the trends. In order to capture non-linear trends in sea level, a locally weighted running line smoother called LOESS (Cleveland, 1979; Cleveland and Devlin, 1988; Hastie and Tibshirani, 1990) was applied and compared with the robust linear regression trend. LOESS is often used to esti- 
mate non-linear trends where non-linearity is important. Note that two nearby observations are shown for Hong Kong, obtained from the records at PSMSL. These nearby stations (HK and TP) show similar long-term trends, except for possible phase differences and local deviations. The existence of local variations is not surprising and emphasizes the spatial inhomogeneity of sea level variations. The long-term increase in sea level is clear between 1950 through the early 2000s, and some major decadal oscillations can also be observed (e.g., in the 1950s, late 1970s, and late 1990s). Although we recognize the likely influence of tectonic effects, the time scales associated with tectonic subsidence and uplift are expected to be much longer than the timescales we refer to here.

Figure 3(b) shows the mean sea level variations at Xiamen and Penghu. Both tide gauges show similar peaks during the 1970s. The sudden decrease in slope around 1980 is striking. To verify this tendency, and to compare the actual rates of change in sea level, we have calculated and compared the yearly forward first differences, which represent the yearly slopes (Fig. 5). The average of all slopes during a particular period represents the longterm mean slope (linear trend) for that period. We find that this approach is better and easier to apply than fitting a straight line to the entire record because straight linear regressions completely ignore the possibility that the long-term slope may be non-linear, as shown here.

Figure 4 shows the remaining observations north of Taiwan. All stations exhibit similar trends, except Keelung. The large increase in sea level during the late 1970 s is much weaker and limited at Keelung. An extraordinary rise at Keelung is consistent with the timing of the last reinstallation of that station in the early $90 \mathrm{~s}$ (confirmed by the CWB documents). The artificial effect resulting from the station structure cannot be excluded in this case for the last decadal records in Keelung. Nevertheless, the 18-month moving mean for Keelung detects weaker but still increasing trends for the same period, which are generally consistent with those detected by the other stations. Figure 5 clearly shows the rates of change for each year. The rates of increase drop rapidly after 1980 and even become negative, upon occasion, by the late 1990s. We note that during the period between about 1960 and 2000, although the rates of change vary, there is some degree of constancy. In general, these tide-gauge data show similar trends and decadal variations with different maxima occurring locally with significant phase differences (e.g., late 1950s early 1960s: decreasing; 1970s: increasing; 1980s: increasing weakly; late 1990s: increasing), but nevertheless suggest that regional sea level is varying in a coherent manner at the lower frequencies. These characteristics are summarized below.

1. Long-term increases in SLR since 1950 are observed consistently at all stations, regardless of the analy- sis technique employed. Similar trends are frequently observed, except for local differences that occur on shorter time scales (e.g., Keelung shows a very smooth long-term trend while variations can still be detected from the moving mean).

2. The non-linear trends of sea level in the regional seas around Taiwan contain a significant amount of interannual and decadal variability, the existence of which is coherent in all records with remarkable falls and rises occurring in a cyclic manner. All stations show SLR maxima during the 1970 s and 1990s. The signals at Penghu and Keelung are weaker due to possible local vertical motions of the measurement platforms.

3. The most recent significant increase of SLR in the regional seas around Taiwan occurred in the late 1990s. Consistent with global and other regional observations, all sea level curves show a rise of more than $10 \mathrm{~mm} / \mathrm{yr}$ followed by a sea level fall accompanying the 1997 1998 ENSO (Fig. 5).

4. In general, the current long-term reconstructions of sea level show clear indications of decadal oscillations. From these long records, variability over the most recent 15 years (1993 2007) may correspond to initially increasing and then decreasing phases (after 2000) of a decadal sea level oscillation. Significant interannual and multiyear variability indicates the need for long records to reliably estimate the long-term rate of SLR from individual sites, which is consistent with previous recommendations (e.g., Douglas, 1997).

\subsection{General SLR features from the tide-gauge and altimetry data over the last 15 years}

Satellite altimetry only became available since the early 1990s. The altimetry-derived rates of sea level variation during the period 1993 2007 in the regional seas around Taiwan are presented in Fig. 6. Five locations are shown around Taiwan and the spatial inhomogeneity is clear. Even though altimetry data show generally increasing trends at all locations, there is considerable spatial variability. Based on the forward first differences from LOESS smoothing of the altimetry data, the mean trend of SLR is $+5.0 \mathrm{~mm} / \mathrm{yr}$ between 1993 and 2007 around Taiwan (Table 2). Linear regression analysis gives a lower rate of $+3.7 \mathrm{~mm} / \mathrm{yr}$ (labeled on panels). This lower rate is not surprising because the non-linear variation (first increasing and then decreasing after 2000) cannot be fully captured by linear regression.

All observations show SLR of at least $+4 \sim 5 \mathrm{~mm} / \mathrm{yr}$ except at location $\mathrm{E}$ (the linear regression trend is only $+0.92 \mathrm{~mm} / \mathrm{yr}$ ), where some satellite observational uncertainties may exist due to the shallowness of the Taiwan Strait (the maximum depth is 60-70 m). Panels B and C, both located east of Taiwan, show quite similar variations (trends and phases, correlation $r=0.95$ ). The sea level 

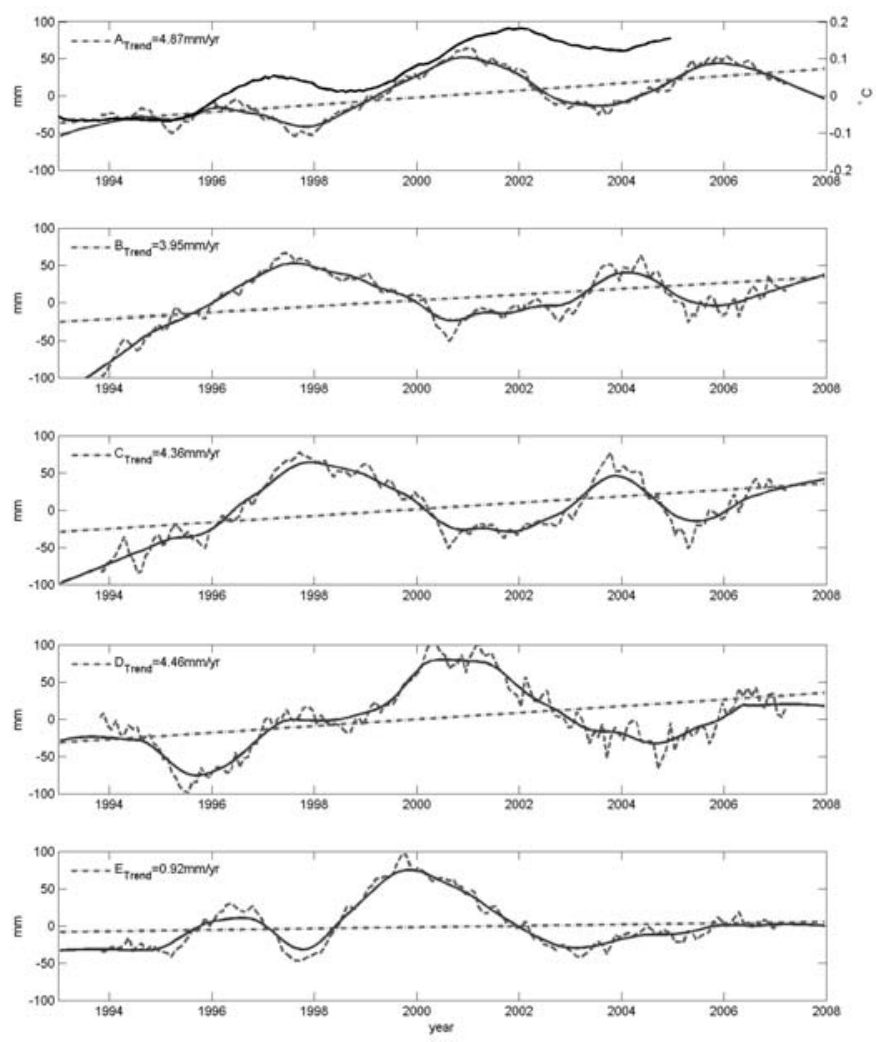

Fig. 6. Altimetry derived rates of sea level variation during 1993-2007 in the regional seas around Taiwan at different locations (see Fig. 2). The straight dash-dotted lines are the linear trends for the whole observation period based on robust linear regression while the solid curves are the non-linear variations estimated by the LOESS analysis. Eighteen-month moving mean filters (shown as dash lines) are also applied. Variation of temperature anomaly in the Pacific is also shown here (top panel) for comparison (black solid line, Palmer et al., 2007).

variations at $\mathrm{E}$ are close to the northeast corner of the SCS and so they should be associated with the regional response in the SCS. The spatial inhomogeneity of sea level trends around Taiwan is not well understood but may be linked to regional ocean dynamic and thermodynamic processes. Previous studies also suggest that the anomaly in sea surface temperature (SSTA) in the SCS is correlated with the eastern Pacific SSTA with a half-year lag (Ose et al., 1997; Xie et al., 2003). Large rates of sea level variation tend to occur east of Taiwan (e.g., in Zones B and C) with a relative maximum SLR around early 1998 (some delayed variations are also observed at other stations), which may be associated with the 1997 1998 El Niño. The relative maximum in the late 1990s is consistent with the tide-gauge data in Figs. 3 and 4, indicating the extensive nature of the SLR signals. This appears to result from the long-term variations in the upper $\mathrm{OHC}$ down to a depth of several hundred meters. The variation in the temperature anomaly above the $14^{\circ} \mathrm{C}$ isotherm in the Pacific Ocean (Palmer et al., 2007; http:// hadobs.metoffice.com/hadgoa/) is also presented in Fig. 6(a) based on an 18-month moving mean. The correlation, $r$, with location $\mathrm{A}$ is as high as 0.91 , with a one-year delay ( $>0.79$ if no phase shift is considered). For all other stations, $r$ is also greater than 0.86 . This analysis provides a more consistent view of the underlying warming and its connection to SLR near Taiwan. When the OHC increases, sea levels at locations $\mathrm{B}$ and $\mathrm{C}$ rise through thermal expansion as a result of advection from the warm Kuroshio. The OHC is discussed further in Section 4.

In order to further investigate sea level variations for the most recent 15 years and to verify the coastal tidegauge data, the altimetry-derived SLRs (location E) are also compared with the sea level variations at the nearest coastal tide gauge (Kaohsiung, KS) for the same time period in Fig. 7. The altimetry-derived sea level anomalies are in generally good agreement with the tide-gauge data, including the minimum around 1996 and maximum around 2000. Based on the LOESS analysis, the estimated SLR values from 1993 to 2007 according to the tide-gauge and altimetry data (E) are $+3.6 \mathrm{~mm} / \mathrm{yr}$ and $+3.1 \mathrm{~mm} / \mathrm{yr}$, respectively. The difference is small. However, a large 
Table 2. Mean sea level rise ( $\mathrm{mm} / \mathrm{yr}$ ) from the tide gauges and altimetry (estimated by LOESS analysis).

\begin{tabular}{lcccc}
\hline & 1993 2003 & 1961 2003 & 1955 2003 & Entire periods \\
\hline Hong Kong (HK) & 4.0 & 2.1 & 0.2 & $0.6(1951 \sim 2006)$ \\
Kanmen (KM) & 2.0 & 1.7 & - & $1.4(1960 \sim 2007)$ \\
Kaohsiung (KS) & 7.3 & 4.9 & 3.4 & $1.9(1949 \sim 2006)$ \\
Keelung (KL) & -0.3 & 0.8 & 0.5 & $0.8(1948 \sim 2006)$ \\
NAHA (NH) & 3.5 & 2.5 & - & $3.4(1968 \sim 2007)$ \\
NASE (NS) & 4.3 & 0.4 & - & $-0.1(1959 \sim 2007)$ \\
Penghu (PH) & 17.1 & 4.3 & 11.0 & $10.5(1956 \sim 2006)$ \\
Xiamen (XM) & 7.8 & 2.7 & 2.3 & $2.3(1955 \sim 2003)$ \\
Mean (tide gauges) & 5.7 & 2.4 & 3.5 & \\
Mean (altimetry) & 5.3 & - & - & $5.0(1993 \sim 2007)$ \\
Global (IPCC, 2007) & 3.1 & 1.8 & - & \\
\hline
\end{tabular}

difference is found with linear regression analysis: the trends are $+7.54 \mathrm{~mm} / \mathrm{yr}$ and $+4.46 \mathrm{~mm} / \mathrm{yr}$, respectively. Our results suggest that linear trends may not always be representative for regional sea level variations. The LOESS analysis is well-suited to estimate non-linear trends because it is based on local regression applied to segments of the data rather than regression applied to the entire record (Breaker, 2007). Regardless of the analysis method, the tide-gauge determined trend at Kaohsiung is always larger than that estimated from altimetry. Land subsidence around southwestern Taiwan could be a possible contributing factor. Unfortunately, the actual magnitude of this effect is not known.

After 2001, both types of observations show a pronounced fall; the trend of decreasing sea level continues for the next four years, followed by increasing sea level after 2005 (Fig. 7). These variations in sea level are an important feature in the SCS (e.g., Cheng and Qi, 2007). We also find that the variations in the tide-gauge determined SLR agree well with the variations in the temperature anomalies in the SCS (see the thick solid line in Fig. 7 for the long-term, depth-integrated temperature anomaly down to $300 \mathrm{~m}$ in the northeastern SCS). The temperature anomalies and the sea level variations from the two sources are similar except for slight differences during the 1997 1998 El Niño. The altimetry-derived sea levels show a larger increase, while both tide-gauge data and the observed temperature anomaly exhibit similar trends. The agreement between the tide-gauge determined SLR and the temperature anomaly supports the idea that regional ocean warming plays an important role in the observed sea level variations. The correlation is close to 0.9 while it is only 0.81 between the altimetry-derived SLR and the temperature anomaly. Our results suggest that over the last 15 years, sea levels around Taiwan have risen and this appears to be associated with thermal expansion. The recent large variations in the regional seas around Taiwan could be transient, as suggested by the increasing

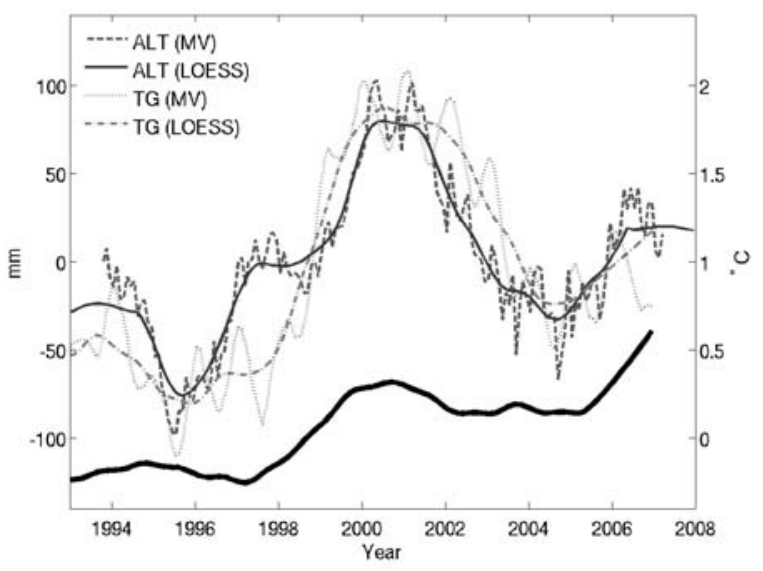

Fig. 7. Comparison between the altimetry-derived (location E) and tidal gauge (KS) observed sea level variations. Both eighteen-month moving-averaged (MV) time-series and non-linear LOESS analysis results are shown. The time-series, depth integrated (down to $300 \mathrm{~m}$ ) temperature anomaly in the northeast SCS is also shown here as a thick solid line (Ishii et al., 2006).

rates of SLR during the late 1990s followed by decreases in the rate of SLR.

\subsection{Regional variations and the relation between the re- gional seas around Taiwan and the global ocean}

Table 2 compares the mean sea level trends during several periods since 1955 . These are mainly computed from data collected at eight coastal stations in the regional seas around Taiwan. For the recent period of 1993 2003, the tide-gauge determined mean SLR is $+5.7 \mathrm{~mm} / \mathrm{yr}$ ( Table 2), which is slightly higher than that estimated from the altimetry data $(+5.3 \mathrm{~mm} / \mathrm{yr})$. These values are also similar to those estimated in other western Pacific (WP) regions and are much higher than the observed global 
mean of $+3.1 \pm 0.7 \mathrm{~mm} / \mathrm{yr}$ for the same period (IPCC, 2007). For example, Kang et al. (2005) reported average trends of $+5.4 \mathrm{~mm} / \mathrm{yr}$ for the entire Sea of Japan and +6.6 $\mathrm{mm} / \mathrm{yr}$ for the southern part during 1992 2001. Cheng and Qi (2007) found a rise rate of $+11.3 \mathrm{~mm} / \mathrm{yr}$ during 1993 2000 and, subsequently, a decline rate of -11.8 $\mathrm{mm} / \mathrm{yr}$ during 2001 2005 in the SCS. These large rates of change in the regional seas around Taiwan may be an extension of the larger trend in the WP revealed in earlier results (Cabanes et al., 2001; Li et al., 2002; Kang et al., 2005), reflecting the regional response to interannual climate variability. In recent decades, the altimetry data also reveal a large-scale pattern of sea level change, with sea level falling in the eastern Pacific and rising in the WP (IPCC, 2007).

Based on the coastal tide-gauge data from locations near Taiwan, Table 2 also shows mean rates of rise of $+3.5 \mathrm{~mm} / \mathrm{yr}$ from 1955 2003 and $+2.4 \mathrm{~mm} / \mathrm{yr}$ from 1961 2003, respectively. The differences indicate large increasing sea levels during the 1950s with substantial interannual variability. These values are also relatively large compared with the global mean value of +1.8 $\mathrm{mm} / \mathrm{yr}$ derived from the records of 25 tide-gauge stations around the world for the same period (e.g., IPCC, 2007). Similar to the recent 15 -year trend, the relatively high value could be due primarily to regional influences. Note that the recent increasing rate of SLR (1993 2003) is more than double the mean rate over the last 50 years. The ratio is consistent with other global estimates (IPCC, 2007), except that the rates we have observed are higher. In the next section we further discuss the possible causes of the regional SLR around Taiwan.

\section{Possible Mechanisms for the Long Term Trends}

\subsection{Upper ocean warming}

The results presented in Section 3 contain a large range of rates of relative sea level change and indicate that the recent variations in SLR are closely correlated with the local OHC. In particular, the rates of increase have been relatively large over the last 50 years, which is evident from all records. Here we further examine the historical ocean thermal conditions (Ishii et al., 2006) in the upper ocean of the study area.

Antonov et al. (2005) and Ishii et al. (2006) estimated an approximate value of $+1.2 \pm 0.5 \mathrm{~mm} / \mathrm{yr}$ for the global SLR (1993 2003) that is due to thermal expansion in the upper $700 \mathrm{~m}$. This is also subject to significant regional redistributions of heat and spatially inhomogeneous patterns. Thus, SLR may result more from eustatic effects at high latitudes while ocean warming may dominate at lower latitudes. Ishii et al. (2006) showed that the thermosteric component dominates in sea level change around Japan. They also found that tide-gauge

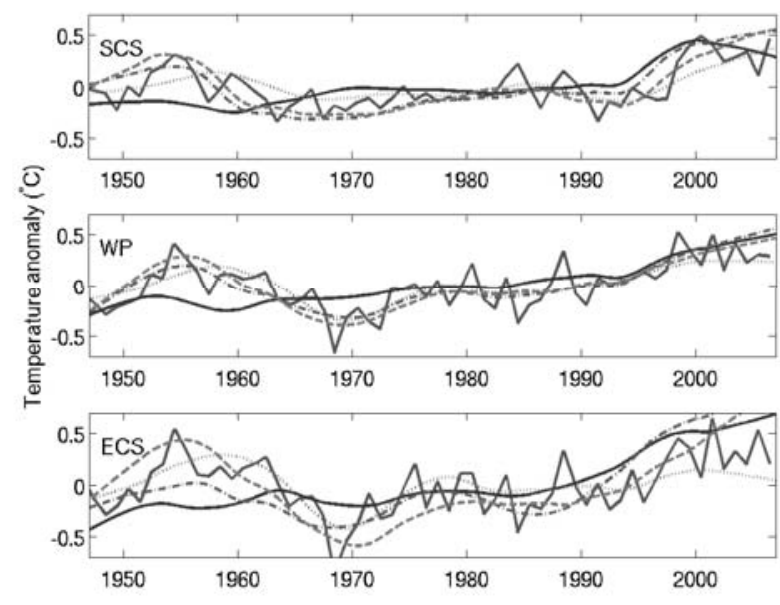

(a)

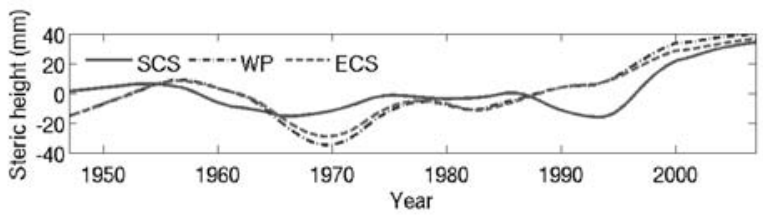

(b)

Fig. 8. LOESS analysis of the ocean subsurface temperature and steric height anomaly since 1946 (Ishii et al., 2006). (a) Top three panels: SCS, WP and ECS, respectively. Temperature anomaly at 0 (solid lines), 50 (dashed dot lines), 100 (dashed lines) and 200 (dots) $\mathrm{m}$ depth. The $0-300 \mathrm{~m}$ depth averaged temperature anomaly is also shown as the blue solid lines (without LOESS smoothing). (b) Bottom panel: Derived steric height for three chosen regions.

agreement is usually better in areas where the thermosteric effects are regarded as a dominant contributor to steric SLR. Figure 8(a) shows a LOESS analysis of the Ishii subsurface temperature anomaly data since 1946 at different depths (Ishii et al., 2006). The 0-300 m depth averaged temperature anomaly is also shown as blue solid lines (without smoothing). We divided the $1^{\circ} \times 1^{\circ}$ resolution temperature data into three different regions: the SCS, WP and ECS. These represent the regional seas to the south, east, and north of Taiwan. Similar to the other regions in the North Pacific, there is a consistent warming signal in Fig. 8(a). The corresponding steric sea level variation for each region is also presented in Fig. 8(b), which shows clear thermal influences. Analysis of individual regions shows that the upper layer temperature has increased by more than $1^{\circ} \mathrm{C}$ over the last 60 years. The Pacific has been warming since the 1950s and two major peaks, in the 1950 s and the late 1990 s, are observed. A minor warming peak in the late 1970 s has also been observed in WP and ECS, similar to those shown by the observed tide-gauge data near Taiwan (e.g., there are posi- 
tive but decreasing forward differences around the late 1950s and large positive forward differences around the 1970s and 1990s in Fig. 5). Most of the tide-gauge data correlate well with steric height variations in the nearby regions. For example, the correlation between the observed sea level variation at station $\mathrm{NH}$ and the estimated steric height variation for ECS in Fig. 8(b) can be as high as 0.92 . The lowest correlation is observed at station NS (0.48). Note that the high sea levels usually correspond to high temperature anomalies at 100-300 m depths (100 $\mathrm{m}$ depth shown as dashed lines and $200 \mathrm{~m}$ depth shown as dots), which are particularly clear for the observed warming during the 1950 s while the surface temperature was relatively cool. This suggests that, consistent with the nearby regions (e.g., Kang et al., 2005), thermal expansion could be a major contributor to the observed SLR around Taiwan, at least during the last 50 60 years.

Comparing the regional warming with the global ocean, Antonov et al. (2005) and Ishii et al. (2006) estimated an average thermosteric trend of $0.33 \mathrm{~mm} / \mathrm{yr}$ and $0.36 \mathrm{~mm} / \mathrm{yr}$, respectively, during the period 1955 2003. The rate of thermosteric SLR varies significantly with time. Both the Levitus and Ishii datasets show that a significant rise occurred from the late 1960s to the late 1970s, followed by a small decrease. Another large rise began in the 1990s but decreased after 2003. These patterns indicate larger accelerations in SLR during the 1950s, late 1970 s, and late 1990s. Interestingly, they are quite consistent with the regional SLR trends shown in Table 2 and Figs. 5 and 8.

This evidence suggests that SLR in the regional seas around Taiwan tends to be dominated by decadal signals in the regional $\mathrm{OHC}$, while the eustatic influence appears to be limited. This pattern may be associated with sea level variations that affect the entire Pacific basin. Since the Pacific is strongly influenced by interannual variability associated with ENSO (an ocean-atmosphere coupled mode in the climate system), the ENSO-related ocean variability may account for the largest fraction of variance in spatial patterns of thermosteric sea level which has caused the largest increases in SLR over the last few decades (IPCC, 2007; Sun and Yu, 2009). Similarly, the observed SLR trends (or thermosteric sea levels) could be partially associated with North Pacific Gyre Oscillation (NPGO) or Pacific Decadal Oscillation (PDO), which may be related to the basin-wide regime shift that occurred in 1976 1977. In either case, thermosteric effects most likely explain the decadal variations we have observed in the regional tide-gauge data.

\subsection{Other possible factors}

Other possible influences on sea level variations include changes in water masses as a result of water exchange with other surface reservoirs, such as river inflow, atmosphere, continental water, glaciers, and ice sheets (Church et al., 2004; IPCC, 2007). However, the eustatic contributions from the continents and melting sea ice (Antonov et al., 2002; Munk, 2003) may be locally significant on decadal scales. In the area of interest, one possible mass source is river discharge, which could only cause small local steric increases in sea levels. Another possible water mass input results from the atmosphere. This has not been well defined and quantified, and is a topic that requires further study. Furthermore, the water impounded by the artificial reservoirs could cause negative feedback on SLR (Chao et al., 2008). These overall water mass changes are difficult to estimate based on available observations. In any case, we find little evidence for eustatic contributions to the observed SLR in the regional seas around Taiwan.

Ocean circulation changes may also cause sea level variations. To the best of our knowledge, the long-term regional ocean circulation has not changed significantly in terms of the overall transport. Finally, tectonic movements or local subsidence (e.g., due to groundwater withdrawal and terrestrial storage) could introduce a large amount of uncertainty. Some stations may be subsiding, thus giving even higher apparent SLR rates. Other relevant results show that local subsidence is occurring along many coastal regions in Asia. This could be due to the draining of underground aquifers in coastal regions to supply fresh water. However, the observations acquired during different periods show that long-term relative sea level variations should not be significantly affected by local effects. These factors may primarily contribute to the observed inhomogeneous patterns between the stations but do not affect the similarity of the long-term trends dominated by regional sea level evolution.

\section{Summary}

We present sea level trends and variability over a 50 -year period for the regional seas around Taiwan. Similar trends and patterns are detected at most stations. For the period 1993 2003, the available tide-gauge records show an average rate of SLR of about $+5.7 \mathrm{~mm} / \mathrm{yr}$, which is more than twice that observed during 1961 2003 (+2.4 $\mathrm{mm} / \mathrm{yr})$. This implies that there have been higher accelerations in SLR in recent decades. The rise rate is quite consistent with previous estimates from nearby areas in the western Pacific and is generally higher than the global mean. Larger spatial and temporal variations are also found in the tide-gauge data.

Satellite altimetry is also used to verify the regional sea level variations over the past 15 years. For the period 1993 2003, the altimetry-derived SLR is $+5.3 \mathrm{~mm} / \mathrm{yr}$. There is good agreement between the altimetry and the tide-gauge data. Further comparisons with regional OHC suggest that thermal expansion and heat advection in the 
upper layer make a significant contribution to long-term sea level variations in this area (the correlation is higher than 0.9). Specifically, thermosteric sea level variations appear to contribute strongly to the observed SLR around Taiwan. The interannual and decadal oscillations in sea level could result from coupled ocean-atmospheric climate perturbations such as ENSO and/or the PDO in the North Pacific.

Based on the tide-gauge data, the long-term regional patterns in sea level show clear decadal scale variations. Since the altimetry records are relatively short, the longterm trend of SLR can only be estimated from the tidegauge records. Our results suggest that the time series signal from the altimetry is only part of a longer-term, larger-scale signal. This implies that caution should be employed when attempting to forecast SLR using only satellite altimetry (after 1993). Further study of the ocean heat budget could provide additional information on the cause of the decadal oscillations in the $\mathrm{OHC}$, which is not well understood at present. Further studies based on general ocean circulation models are required.

\section{Acknowledgements}

The authors acknowledge the financial support for this work by National Science Council, Taiwan (grant NSC972627M002024). Useful comments from two anonymous reviewers are deeply appreciated.

\section{References}

Antonov, J. I., S. Levitus and T. P. Boyer (2002): Steric sea level variations during 1957-1994: Importance of salinity. J. Geophys. Res.-Oceans, 107, doi:10.1029/2001jc000964.

Antonov, J. I., S. Levitus and T. P. Boyer (2005): Thermosteric sea level rise, 1955-2003. Geophys. Res. Lett., 32, L12602, doi:10.1029/2005GL023112.

Breaker, L. C. (2007): A closer look at regime shifts based on coastal observations along the eastern boundary of the North Pacific. Cont. Shelf Res., 27, 2250-2277.

Cabanes, C., A. Cazenave and C. Le Provost (2001): Sea level rise during past 40 years determined from satellite and in situ observations. Science, 294, 840-842.

Cazenave, A. and R. S. Nerem (2004): Present-day sea level change: Observations and causes. Rev. Geophys., 42, RG3001, doi:10.1029/2003rg000139.

Chao, B. F., Y. H. Wu and Y. S. Li (2008): Impact of artificial reservoir water impoundment on global sea level. Science, 320, 212-214.

Chelton, D. B. and D. B. Enfield (1986): Ocean signals in tide gauge records. J. Geophys. Res., 91, 9081-9098.

Chen, X. Q. (1991): Sea-level changes since the early 1920s from the long records of 2 tidal gauges in Shanghai, China. J. Coast. Res., 7, 787-799.

Cheng, X. H. and Y. Q. Qi (2007): Trends of sea level variations in the South China Sea from merged altimetry data. Global Planet. Change, 57, 371-382.

Church, J. A., N. J. White, R. Coleman, K. Lambeck and J. X.
Mitrovica (2004): Estimates of the regional distribution of sea level rise over the 1950-2000 period. J. Climate, 17, 2609-2625.

Cleveland, W. S. (1979): Robust locally weighted regression and smoothing scatterplots. J. Amer. Stat. Assoc., 74, 829836.

Cleveland, W. S. and S. J. Devlin (1988): Locally weighted regression: An approach to regression analysis by local fitting. J. Amer. Stat. Assoc., 83, 596-610.

Douglas, B. C. (1997): Global sea rise: A redetermination. Surv. Geophys., 18, 279-292.

Du, T., Y. H. Tseng and X. H. Yan (2008): The impacts of tidal currents and Kuroshio intrusion on the generation of nonlinear internal waves in Luzon Strait. J. Geophys. Res. -Oceans, 113, C08015, doi:10.1029/2007JC004294.

Emery, W. J. and R. E. Thomson (2004): Data Analysis Methods in Physical Oceanography. Elsevier, Amsterdam, 638 pp.

Hastie, T. and R. Tibshirani (1990): Exploring the nature of covariate effects in the proportional hazards model. Biometrics, 46, 1005-1016.

Ho, C. S. (1986): A synthesis of the geologic evolution of Taiwan. Tectonophysics, $\mathbf{1 2 5}, 1-16$.

IPCC (2007): Climate Change 2007: The physical science basis. Summary for policy makers. Contribution of working group I to the fourth assessment report. The Intergovernmental Panel on Climate Change, http://www.ipcc.ch/ SPM2feb07.pdf

Ishii, M., M. Kimoto, K. Sakamoto and S. I. Iwasaki (2006): Steric sea level changes estimated from historical ocean subsurface temperature and salinity analyses. J. Oceanogr., 62, 155-170.

Kang, S. K., J. Y. Cherniawsky, M. G. G. Foreman, H. S. Min, C. H. Kim and H. W. Kang (2005): Patterns of recent sea level rise in the East/Japan Sea from satellite altimetry and in situ data. J. Geophys. Res.-Oceans, 110, doi:10.1029/ 2004 jc002565.

Levitus, S., J. I. Antonov, T. P. Boyer and C. Stephens (2000): Warming of the world ocean. Science, 287, 2225-2229.

Levitus, S., J. Antonov and T. Boyer (2005): Warming of the world ocean, 1955-2003. Geophys. Res. Lett., 32, doi:10.1029/2004g1021592.

Li, L., J. D. Xu and R. S. Cai (2002): Trends of sea level rise in the South China Sea during the 1990s: An altimetry result. Chinese Sci. Bull., 47, 582-585.

Lisitzin, E. (1974): Sea Level Changes. Elsevier Oceanography Series (8), Elsevier, Amsterdam.

Metzger, E. J. and H. E. Hurlbert (2001): The importance of high horizontal resolution and accurate coastline geometry in modeling South China Sea inflow. Geophys. Res. Lett., 101, 12331-12352.

Miller, L. and B. C. Douglas (2004): Mass and volume contributions to twentieth-century global sea level rise. Nature, 428, 406-409.

Munk, W. (2003): Ocean freshening, sea level rising. Science, 300, 2041-2043.

Ose, T., Y. K. Song and A. Kitoh (1997): Sea surface temperature in the South China Sea-an index for the Asian monsoon and ENSO system. J. Meteor. Soc. Japan, 75, 
1091-1107.

Palmer, M. D., K. Haines, S. F. B. Tett and T. J. Ansell (2007): Isolating the signal of ocean global warming. Geophys. Res. Lett., 34, L23610, doi:10.1029/2007g1031712.

Schrama, E., R. Scharroo and M. Naeije (2000): Radar Altimeter Database System (RADS): Towards a generic multisatellite altimeter database system, final report, $88, \mathrm{SRON} /$ BCRS publ., USP-2 report 00-11.

Sun, F. and J.-Y. Yu (2009): A 10-15 year Modulation cycle of ENSO intensity. J. Climate, 22, 1718-1735.

Tushingham, A. M. and W. R. Peltier (1991): Ice-3G-A new global-model of late pleistocene deglaciation based upon geophysical predictions of postglacial relative sea-level change. J. Geophys. Res.-Solid Earth and Planets, 96, 44974523.

Wang, Y. (1998): Sea-level changes, human impacts and coastal responses in China. J. Coast. Res., 14, 31-36.

Woodworth, P. L. and R. Player (2003): The permanent service for mean sea level: An update to the 21 st century. J. Coast. Res., 19, 287-295.

Xie, S. P., Q. Xie, D. X. Wang and W. T. Liu (2003): Summer upwelling in the South China Sea and its role in regional climate variations. J. Geophys. Res.-Oceans, 108, doi:10.1029/2003cj001867. 